\title{
Cutaneous Metastases of Internal Cancers: A Retrospective Study about 12 Cases
}

\section{K. Oualla*, S. Arifi, N. Mellas and O. El mesbahi}

Department of Medical Oncology, Hassan II University Hospital, Fez, Morocco

\begin{abstract}
The skin is an uncommon site of metastasis of the internal cancers. The majority of cutaneous metastases are diagnosed after the primary cancer; but they can be the telltale sign of an unknown malignancy. They represent a sign of poor prognosis with a survival rate not exceeding a few months. We report the results of a retrospective study conducted in department of medical oncology at Hassan II University Hospital, including 12 patients with cutaneous metastases. The aim of this work is to show the rarity of skin as metastatic site, to analyze the clinical aspects of cutaneous metastasis, the most criminalized primary cancers and the prognosis value of this metastatic localization.
\end{abstract}

Keywords: Skin; Metastasis; Chemotherapy

\section{Introduction}

Cutaneous metastases of internal malignant tumors are rare. They can have variable clinical appearances and can mimic benign skin lesions. They are usually seen in patients with advanced disease, but they can be the presenting lesion. They are frequently a sign of poor prognosis.

\section{Patients and Methods}

It is a retrospective study, including patients with histological proven cutaneous metastasis treated in the department of medical oncology at Hassan II University Hospital between January 2007 and October 2011.

\section{Results}

During the period of study, only 12 cases of cutaneous metastases were collected. It represents $0.46 \%$ from all cancer patients collected in this period. In all cases, cutaneous metastases were confirmed histologically. It was characterized in 8 cases by the presence of dermal tumor proliferation, in 2 cases by hypodermal proliferation and in the 2 other cases by both dermal and hypodermal malignant development. Vascular invasion was noted in 6 cases. The mean age was 55,3 years (range: $40-70$ ), with female predominance ( 8 cases). The cutaneous metastases originate from breast cancer $(n=6)$, lung cancer $(\mathrm{n}=3)$, hepatocellular carcinoma $(\mathrm{n}=1)$, larynx carcinoma $(\mathrm{n}=1)$, and biliary tract carcinoma $(\mathrm{n}=1)$. In 7 cases, the cutaneous metastases revealed the primary cancer. In 5 cases, cutaneous metastases occurred after diagnosis of primary tumors, with a median of 6 months (2-18 months). Their diagnosis was simultaneous with the discovery of other metastatic sites. Their localizations were in chest $(n=6)$ (Figures 1,2), neck $(n=2)$, scalp $(n=1)$, forearms $(n=1)$, umbilical region $(n=1)$ and face $(n=1)$ (Figure 3$)$. The skin lesion was single in 4 cases and multiple in 8 cases. They appear as erythematous and nodular painless lesions in most cases. Patient with umbilical nodular lesion (Sister Joseph's nodule) revealing biliary tract carcinoma died before treatment. Palliative chemotherapy was started in 11 patients. It was based on regimens specific to the primary tumor. Chemotherapy has allowed the improvement of cutaneous manifestations (Figures 4, 5). In our series 6 patients with breast cancer are still alive with a median follow-up of 10 , 5 months. 5 patients died despite chemotherapy with a median survival not exceeding a few months (Table 1).
Cutaneous metastasis is defined by the presence and development, in the skin surface, of a malignant process whose origin is located at distance. The occurrence of cutaneous spread of internal malignancies is quite rare, despite the fact that the skin is one of the largest organs of the human body $[1,2]$. The frequency of cutaneous metastases is low, ranging from 0.3 to $9 \%$ according to the literature [3]. It puts the skin at the $12^{\text {th }}$ place among the metastatic sites in cancer.

Cancer cells can invade the skin through the lymphatic, hematogenous or direct extension, but only lesions not contiguous to the primary tumor are considered as metastases. This restriction excludes Paget's disease of the breast, because these lesions represent a direct extension of cancer cells to the skin. Skin implant metastasis has been observed after percutaneous radio-frequency therapy of a liver metastasis of a colorectal carcinoma [4].

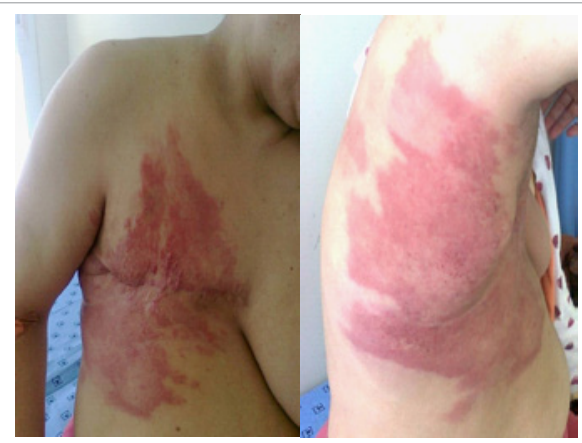

Figure 1: Multiple erythematous lesions located on the chest originating from breast cancer (Before chemotherapy).

*Corresponding author: Karima Oualla, Department of Medical Oncology, Hassan II University Hospital, Fez, Morocco, Tel: 002126766102 67; Fax: 00 2125356137 25; E-mail: karimarauf@hotmail.com

Received December 08, 2011; Accepted May 28, 2012; Published May 30, 2012

Citation: Oualla K, Arifi S, Mellas N, El Mesbahi O (2012) Cutaneous Metastases of Internal Cancers: A Retrospective Study about 12 Cases. J Cancer Sci Ther 4 155-157. doi:10.4172/1948-5956.1000131

Copyright: $\odot 2012$ Oualla K, et al. This is an open-access article distributed under the terms of the Creative Commons Attribution License, which permits unrestricted use, distribution, and reproduction in any medium, provided the original author and source are credited. 
Citation: Oualla K, Arifi S, Mellas N, El Mesbahi O (2012) Cutaneous Metastases of Internal Cancers: A Retrospective Study about 12 Cases. J Cancer Sci Ther 4: 155-157. doi:10.4172/1948-5956.1000131

Most common sites of cutaneous metastases are the neck and head region and the trunk which is consistent with our results. The epigastric area seems to be particular prone for cutaneous spread of metastases. Periumbilical metastasis is also known as Sister Mary Joseph's nodule [5]. On the other site, metastases on the limbs are even rarer [6,7].

The most common primary malignancies in males are lung cancer and colon cancer. In females breast cancer is the most common with a cutaneous spread $[8,9]$. There is a very low percentage of renal, thyroid gland, ovarian carcinoma, and bladder cancer with cutaneous filiae [10-14]. Extremely rare are cutaneous metastases in carcinoids or chordoma $[15,16]$. Indeed, in our study breast cancer is the most

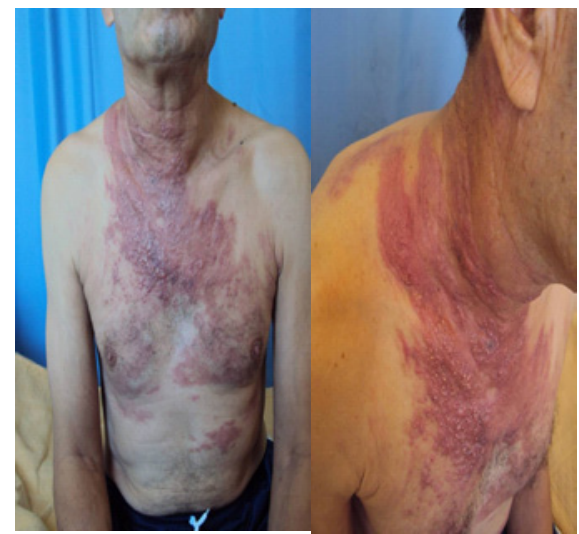

Figure 2: Chest localization of cutaneous metastasis revealing lung cancer (Before chemotherapy).

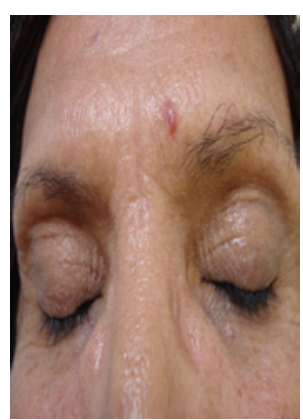

Figure 3: Single erythematous nodular lesion of the face revealing hepatocellular carcinoma.

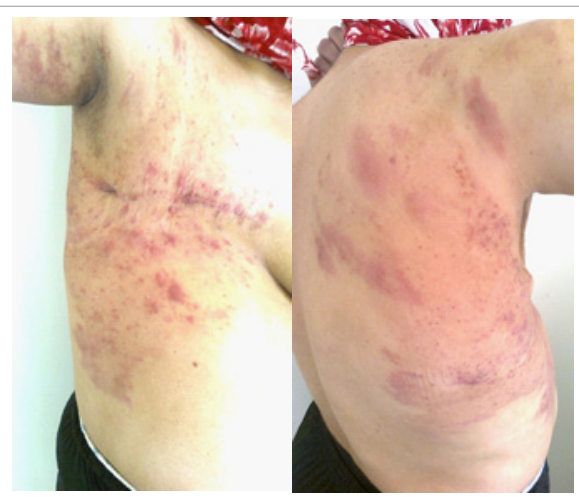

Figure 4: Multiple erythematous lesions located on the chest originating from breast cancer (after chemotherapy).

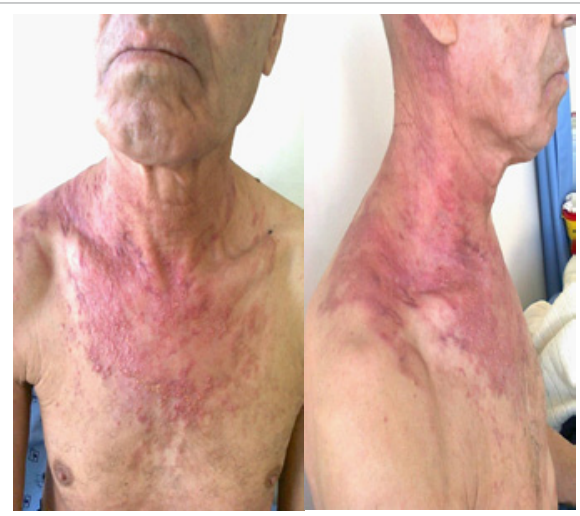

Figure 5: Chest localization of cutaneous metastasis revealing lung cancer (After chemotherapy).

implicated in women and it is lung cancer which is the most common in men.

The most common clinical presentation of cutaneous spread of internal cancer is the developments of nodules, usually firm and painless [17]. However, other clinical presentations include neoplastic alopecia, carcinoma erysipelatoides, erythema annular like, herpetiform or zosteriform, target-like, pyodermatic, and morphea-like lesions [18].

The confirmation of a cutaneous metastasis is not always simple. Fine needle aspiration cytology may be used as a minimal invasive diagnostic tool [9], but complete excision is still the method of choice to ensure the best quality of histopathologic examination.

Histology revealed a variable morphological differentiation, the cells are undifferentiated and frequently do not allow the recognition of the primary tumor [1]. They rarely keep the histological characters recognizable of the primary tumor. The metastases can involve dermis, hypodermis or both with sometimes presence of vascular invasion.

Though cutaneous metastases by themselves rarely cause any severe medical problems, they may be a sign of unknown internal malignancy, recurrence of malignant disease or a preterminal event [2]. In many cases, spread to the skin is a sign of systematic spread of disease and therefore a sign of poor prognosis with low survival [2, 19,20]. High-resolution and Color Doppler sonography can be helpful in the evaluation of skin metastasis [21]. Hypo echoic, irregular nodules with high vascularity are highly suspicious of metastasis. In any case they deserve a histopathologic examination that should be accomplished by immunostaining in case of discrepancies to the presumed primary cancer.

Effective treatment depends on treatment of the underlying tumor. Palliative care is given if lesions are asymptomatic and the primary cancer is untreatable. This care includes keeping lesions clean and dry and debriding the lesions if they are bleeding or crusted. Hydrocolloid dressings may be used to help prevent secondary infection [22]. Local treatment is conceivable in the case of a single lesion or in order to improve life quality (pain). The single small metastasis can be treated surgically (excision), for multiple lesions grouped, or very painful lesions, they can be irradiated. But chemotherapy remains the standard treatment of metastatic disease. It must be based on regimens specific to the primary tumor.

Despite treatments, cutaneous metastasis is a sign of poor prognosis with a survival rate not exceeding a few months [2]. 
Citation: Oualla K, Arifi S, Mellas N, El Mesbahi O (2012) Cutaneous Metastases of Internal Cancers: A Retrospective Study about 12 Cases. J Cancer Sci Ther 4: 155-157. doi:10.4172/1948-5956.1000131

\begin{tabular}{|c|c|c|c|c|}
\hline Primary cancer & Number of cases & Topography of cutaneous lesion & Treatment & Evolution \\
\hline Breast & 6 & $\begin{array}{l}{ }^{*} \text { Chest }(5) \\
{ }^{*} \text { Scalp (1) }\end{array}$ & Chemotherapy & $\begin{array}{c}\text { Clinical response } \\
(>50 \% \text { in all cases) } \\
\text { All patients still alive } \\
\text { (median survival : } 10,5 \text { months) }\end{array}$ \\
\hline Lung & 3 & $\begin{array}{l}{ }^{*} \text { Chest } \\
{ }^{*} \text { Neck } \\
{ }^{*} \text { Forearms }\end{array}$ & Chemotherapy & $\begin{array}{c}{ }^{*} \text { Clinical response }(30 \%) \text { then progression }=>\text { death } \\
{ }^{*} \text { Disease progression }=>\text { death } \\
{ }^{*} \text { Disease progression }=>\text { death }\end{array}$ \\
\hline Hepatocellular carcinoma & 1 & Face & Chemotherapy & *Disease progression => death \\
\hline Biliary tract & 1 & Peri-umbilical & - & Death \\
\hline Larynx & 1 & Neck & Chemotherapy & Current \\
\hline
\end{tabular}

Table 1: Topography, origin and outcome of cutaneous metastases.

\section{Conclusion}

The skin is an uncommon site of metastasis of the internal malignancies. The majority of cutaneous metastasis is diagnosed after the primary cancer; it is rarely the telltale sign of an unknown malignancy. Cancers with cutaneous metastasis are frequently metastatic in other sites. The prognosis is poor with low survival rate.

\section{References}

1. Brenner S, Tamir E, Maharshak N, Shapira J (2001) Cutaneous manifestations of internal malignancies. Clin Dermatol 19: 290-297.

2. Lookingbill DP, Spangler N, Sexton FM (1990) Skin involvement as the presenting sign of internal carcinoma. A retrospective study of 7316 cancer patients. J Am Acad Dermatol 22: 19-26.

3. Mueller TJ, Wu H, Greenberg RE, Hudes G, Topham N, et al. (2004) Cutaneous metastases from genitourinary malignancies. Urology 63: 1021-1026.

4. Bonatti H, Bodner G, Obrist P, Bechter O, Wetscher G, et al. (2003) Skin implant metastasis after percutaneous radio-frequency therapy of liver metastasis of a colorectal carcinoma. Am Surg 69: 763-765

5. Samitz MH (1975) Umbilical metastasis from carcinoma of the stomach. Sister Joseph's nodule. Arch Dermatol 111: 1478-1479.

6. DiSpaltro FX, Bickley LK, Nissenblatt MJ, Devereux D (1992) Cutaneous acral metastasis in a patient with primary gastric adenocarcinoma. J Am Acad Dermatol 27: 117-118.

7. Lin CY, Lee CT, Huang JS, Chang LC (2003) Transitional cell carcinoma metastasis to arm skin from the renal pelvis. Chang Gung Med J 26: 525-529.

8. Kanitakis $\mathrm{J}$ (1993) Cutaneous metastases of internal cancers. Presse Med 22: $631-636$

9. Bansal R, Naik R (1998) A study of 70 cases of cutaneous metastases from internal carcinoma. J Indian Med Assoc 96: 10-12.

10. Dahl PR, Brodland DG, Goellner JR, Hay ID (1997) Thyroid carcinoma metastatic to the skin: a cutaneous manifestation of a widely disseminated malignancy. J Am Acad Dermatol 36: 531-537.

11. Zirwas MJ, Hunt S, Logan TF, Abernethy JL, Seraly MP (2000) A painfu cutaneous nodule as the presentation of metastatic transitional cell carcinoma of the renal pelvis. J Am Acad Dermatol 42: 867-868.

12. Kato N, Matsue K, Sotodate A, Tomita Y (1996) Extramammary Paget's disease with distant skin metastasis. J Dermatol 23: 408-414.

13. Vidmar D, Baxter DL Jr, Devaney K (1992) Extensive dermal metastases from primary signet-ring carcinoma of the urinary bladder. Cutis 49: 324-328.

14. Cormio G, Capotorto M, Di Vagno G, Cazzolla A, Carriero C, et al. (2003) Skin metastases in ovarian carcinoma: a report of nine cases and a review of the literature. Gynecol Oncol 90: 682-685.

15. Rodriguez G, Villamizar R (1992) Carcinoid tumor with skin metastasis. Am J Dermatopathol 14: 263-269.

16. Ruiz HA, Goldberg LH, Humphreys TR, Blacklock JB (2000) Cutaneous metastasis of chordoma. Dermatol Surg 26: 259-262.

17. Sariya D, Ruth K, Adams-McDonnell R, Cusack C, Xu X, et al. (2007) Clinicopathologic correlation of cutaneous metastases: experience from a cancer center. Arch Dermatol 143: 613-620.

18. Kaplan RP (1986) Specific cutaneous manifestations of internal malignancy. Adv Dermatol 1: 3-42.

19. Krathen RA, Orengo IF, Rosen T (2003) Cutaneous metastasis: a metaanalysis of data. South Med J 96: 164-167.

20. Koga S, Tsuda S, Nishikido M, Matsuya F, Saito Y, et al. (2000) Renal cel carcinoma metastatic to the skin. Anticancer Res 20: 1939-1940.

21. Giovagnorio F, Valentini C, Paonessa A (2003) High-resolution and color doppler sonography in the evaluation of skin metastases. J Ultrasound Med 22: $1017-1022$

22. Lookingbill DP, Spangler N, Helm KF (1993) Cutaneous metastases in patients with metastatic carcinoma: a retrospective study of 4020 patients. J Am Acad Dermatol 29: 228-236. 